\title{
The Anti-Staphylococcus aureus Effect of Combined Echinophora platyloba Essential Oil and Liquid Smoke in Beef
}

\author{
Zahra Pilevar ${ }^{1}$, Hedayat Hosseini ${ }^{1 *}$, Homa Hajimehdipoor ${ }^{2}$, Farzaneh Shahraz ${ }^{1}$, \\ Leyla Alizadeh ${ }^{1}$, Amin Mousavi Khaneghah ${ }^{3 *}$ and Maryam Mahmoudzadeh ${ }^{1}$ \\ ${ }^{1}$ Food Sciences and Technology Department, National Nutrition and Food Technology Research Institute, \\ Faculty of Nutrition Sciences and Food Technology, Shahid Beheshti University of Medical Sciences, \\ 1981619573 Tehran, Iran \\ ${ }^{2}$ Traditional Medicine and Material Medical Research Center and Department of Traditional Pharmacy, \\ School of Traditional Medicine, Shahid Beheshti University of Medical Sciences, 1981619573 Tehran, Iran \\ ${ }^{3}$ Department of Food Science, Faculty of Food Engineering, State University of Campinas (UNICAMP), \\ Rua Monteiro Lobato 80, 13083-862 Campinas, SP, Brazil
}

Received: February 5, 2016

Accepted: September 16, 2016

\begin{abstract}
Summary
In the current study, the antibacterial effect of Echinophora platyloba essential oil and common liquid smoke (individually and in combination) against Staphylococcus aureus in beef meat samples is investigated. Using an automated microbiological growth analyser and the turbidimetric technique, the minimum inhibitory concentrations (MIC) and the minimum bactericidal concentrations (MBC) of the essential oil and liquid smoke were determined. Anti-S. aureus activity of essential oil and liquid smoke (individually and in combination) was defined by disk diffusion assay, generation time and cell constituent release. Apart from that, the interactions between these two compounds were measured by the checkerboard assay and by calculating the fractional inhibitory concentration (FIC) indices. Related MIC values of essential oil and smoke were found to be 7200 and $5500 \mathrm{mg} / \mathrm{L}$, and MBC values were 8500 and $8000 \mathrm{mg} / \mathrm{L}$, respectively. The conducted organoleptic assay showed that the addition of $0.05 \mathrm{~g}$ of essential oil and $0.6 \mathrm{~g}$ of liquid smoke to $100 \mathrm{~g}$ of meat samples did not have adverse effect on the overall acceptance. Weaker antibacterial effect against Staphylococcus aureus was observed when only Echinophora platyloba essential oil was used than when it was used in combination with liquid smoke.
\end{abstract}

Key words: antibacterial activity, Echinophora platyloba, liquid smoke, Staphylococcus aureus, beef

\section{Introduction}

Staphylococcus aureus as one of the most common bacteria is associated with some worldwide incidents of foodborne intoxication (1). The primary causes of staphylococcal food poisoning have been traced to the personnel who contaminated food products during improper handling and preparation (2). Other sources of contamination in meat industry could be attributed to the utilised equipment and materials, such as improperly cleaned and sanitised meat grinders, knives, saw blades, cutting boards and food storage containers (3).

Meat products can be considered as a potential environment for the growth of pathogens; therefore, in the meat industry application of the natural and synthetic preservatives is unavoidable (4). However, the incorpora-

*Corresponding authors: Phone: +98 212237 6426; Fax: +98 212236 0660; E-mail: hedayat@sbmu.ac.ir (H. Hosseini); Phone: +55 193521 0091; Fax: +55 193521 2153; E-mail: mousavi@fea.unicamp.br (A. Mousavi Khaneghah) 
tion of essential oil as an alternative to synthetic antimicrobials in food encountered some drawbacks and limitations. For instance, to inhibit spoilage in food matrices, the addition of high concentration of antimicrobial agents is required, which often exceeds the acceptable flavour threshold of consumers (5).

The plant Echinophora platyloba belongs to the family Apiaceae (or Umbelliferae), which is commonly used as a flavouring agent in traditional cheese and yogurt products, particularly in Iran (6). Echinophora platyloba is also added to traditional beef stews due to the unique and delicate flavour. Some studies have been carried out to analyse the extracted essential oils from different geographical origins and with various morphologies and genetics (7). These studies have demonstrated several biological properties such as antimicrobial, antioxidant and anti-inflammatory activities. $\beta$-Ocimene has been identified as the main constituent of the investigated E. platyloba from various origins (8).

The smoking of foods, in particular meat, has been introduced as a common method for centuries (9). Liquid smoke application has been increasingly widespread as a suitable replacer for traditional wood smoking due to several advantages, such as more efficient control of polycyclic aromatic hydrocarbon (PAH) content, in which their constituents can be determined by rapid methods (10), better applicability to different food systems and lower environmental pollution (11).

In order to extend the shelf life and improve the food safety, food manufacturers are using different combinations of technologies such as smoking, vacuum packaging, cold storage and natural preservatives such as essential oils (12). The antimicrobial activity of two essential oils has been quantified in a previous study by the microdilution checkerboard method (13).

To our knowledge, no study has been conducted to determine the synergistic or antagonistic interactions between the extracts of essential oils and liquid smoke. Also, despite the vast application of both fresh and dried aerial parts of E. platyloba plant in the Iranian cuisine, no research has been carried out on essential oil applications in food with the evaluation of its acceptable sensory level. The aim of this study is to investigate the chemical composition of E. platyloba essential oil and the PAH content. Also, in vitro antimicrobial properties of E. platyloba essential oil and liquid smoke, alone and in combination, against Staphylococcus aureus in minced meat samples were evaluated taking into consideration their acceptable sensory levels. The treated cultures were spectrophotometrically monitored in order to determine the mechanism of antimicrobial action and bacterial growth kinetics.

\section{Materials and Methods}

\section{Materials}

Lyophilised culture of Staphylococcus aureus ATCC 29213 was obtained from the Pasteur Institute of Iran, Tehran, Iran.

The Echinophora platyloba plant was collected from Hamadan in a temperate mountainous region of Iran, tax- onomically verified and the voucher specimen was deposited (TMRC no. 3720) in the herbarium of Traditional Pharmacy, Shahid Beheshti University of Medical Sciences, Tehran, Iran. The aerial parts (leaves and stems) were collected in the spring season (21 and 22 May 2014) and were exposed to air in a well sheltered and ventilated area for ten days until the moisture was removed.

The commercial liquid smoke was supplied by Red Arrow $^{\circledR}$ Company, Tehran, Iran. Total acidity was 11.2, $\mathrm{pH}=2.8, w$ (carbonyl) $=12.4 \%$ and $\gamma$ (phenols $)=7.6 \mathrm{mg} / \mathrm{mL}$.

Minced beef samples (200 g) obtained from a local butcher's shop were prepared as follows: 0.03, 0.04, 0.05 or $0.06 \mathrm{~g}$ of E. platyloba and $0.5,0.6,0.7$ or $0.8 \mathrm{~g}$ of liquid smoke were added per $100 \mathrm{~g}$ of meat. Meat samples without the added essential oil and liquid smoke were used as control.

\section{Essential oil extraction}

Dried aerial parts of Echinophora platyloba were pulverised to obtain fine powder, which was then hydrodistilled for $4 \mathrm{~h}$. In each distillation, $100 \mathrm{~g}$ of E. platyloba powder were hydrodistilled in a round-bottomed flask (2000 $\mathrm{mL}$ ) fitted to the Clevenger-type apparatus (built by R\&D section of Shahid Beheshti University, Tehran, Iran) with an ice-water-cooled condenser on top of it. Anhydrous sodium sulphate (Fisher Scientific ${ }^{\circledR}$, Loughborough, UK) was used to absorb moisture to avoid any possible change of essential oil. Essential oil yield $(Y / \%)$ was calculated as follows:

$$
Y=(V / m) \cdot 100
$$

where $V$ is the volume of the obtained essential oil (mL), and $m$ is the mass of the sample ( $100 \mathrm{~g}$ of dried plant).

\section{Plant chemical composition analysis}

The essential oil composition was analysed by using gas chromatograph/mass selective detector (GC/MSD) (models 7890 GC and 5975 MSD; Agilent Technologies, Santa Clara, CA, USA) with an HP-5 capillary column (30 $\mathrm{m} \times 250 \mu \mathrm{m}, 0.25 \mu \mathrm{m}$ film thickness), equipped with a split-splitless injection port. The temperature cycle included an initial temperature of $50{ }^{\circ} \mathrm{C}$ (isothermal, $5 \mathrm{~min}$ ) first increased by $5^{\circ} \mathrm{C} / \mathrm{min}$ to 150 and then by $10^{\circ} \mathrm{C} / \mathrm{min}$ to 300 ${ }^{\circ} \mathrm{C}$. The $270{ }^{\circ} \mathrm{C}$ temperature (isothermal) was kept for 5 min. The helium as the carrier gas was maintained at a constant flow of $0.5 \mathrm{~mL} / \mathrm{min}$. The essential oil was diluted in $n$-hexane. Injection volumes were $2 \mu \mathrm{L}$. The components were identified by matching their mass spectra with standards of principal components in Wiley and NIST library data, mostly from the literature $(14,15)$. The component concentration was obtained by semi-quantification of peak area integration from GC peaks and by applying the correction factors.

\section{Determination of liquid smoke chemical composition}

The liquid smoke used in the conducted experiments was analysed using the same GC-MS as mentioned above and according to the recommended temperature program (10): first at $150{ }^{\circ} \mathrm{C}$ for $2 \mathrm{~min}$ and then the temperature 
was increased by $7{ }^{\circ} \mathrm{C} / \mathrm{min}$ to $200{ }^{\circ} \mathrm{C}$, held for $1 \mathrm{~min}$, and then increased by $5{ }^{\circ} \mathrm{C} / \mathrm{min}$ to $250{ }^{\circ} \mathrm{C}$ and held for $1 \mathrm{~min}$. Finally, it was increased rapidly by $20^{\circ} \mathrm{C} / \mathrm{min}$ to $290{ }^{\circ} \mathrm{C}$ and kept for $10 \mathrm{~min}$. The helium was used as the carrier gas at a constant flow of $0.8 \mathrm{~mL} / \mathrm{min}$. The injector and auxiliary temperatures were set to 290 and $280{ }^{\circ} \mathrm{C}$, respectively. Liquid smoke was diluted in methanol. Injection volumes of $2 \mu \mathrm{L}$ were injected in a split mode with the split ratio of 1:50. Finally, the quantification of the compounds was carried out in the selected ion monitoring (SIM) mode and a qualifier ion was picked for each compound.

\section{Minimum inhibitory concentration and minimum bactericidal concentration}

The minimum inhibitory concentration (MIC) values as the lowest concentration of the antimicrobial agent that can inhibit the bacterial growth was determined by the lack of visual turbidity (16). Stock solutions of E. platyloba and liquid smoke were prepared individually. The highest concentration was diluted to 100000 ppm. Fractional dilutions of stock solution from 1000 to 30000 ppm were prepared using tryptic soy broth (TSB; Merck Millipore, Darmstadt, Germany) and Tween 80 (Sigma-Aldrich, St. Louis, MO, USA). To prepare the stock solution, the pure essential oil and liquid smoke were dissolved in $5 \%$ (by volume) of Tween 80, which was used as an emulsifying agent for dispersing essential oil and liquid smoke in the culture medium. Turbidity was measured in two 100-well honeycomb microplates using Bioscreen $\mathrm{C}$ analyser (Oy Growth Curves Abt Ltd, Helsinki, Finland). Changes in absorbance $v s$. time $(18 \mathrm{~h}$ ) were at $\lambda=260 \mathrm{~nm}$ (wideband range) and microbiological growth curves were obtained. A homogenous mixture in individual wells was provided by linear shaking every $15 \mathrm{~min}$ before measurements. Population density of $10^{5}$ cells/mL of S. aureus was obtained by adding serial dilutions from overnight cultures to TSB medium. Triplicate plates with $5 \cdot 10^{9} \mathrm{CFU} / \mathrm{mL}$ of $S$. aureus were prepared by adjusting the absorbance to $A_{260 \mathrm{~nm}}=0.3$. The bacterial suspension was diluted to $10^{7}$ cells $/ \mathrm{mL}$, and then $50 \mu \mathrm{L}$ were added to $300 \mu \mathrm{L}$ of solution in each well. The last two wells served as positive and negative controls, which confirmed the viability of $S$. aureus culture and the sterility of working conditions and solutions, respectively. Experiments were repeated for minimum bactericidal concentration $(\mathrm{MBC})$ determination. A loop full of the content of each clear tube that did not show visible growth, and of the control tube (which contained only TSB and Tween 80 without any antibacterial agent) were spread over a quarter of the plate on tryptic soy agar (TSA; Merck Millipore) medium. The plate was incubated at $37^{\circ} \mathrm{C}$ overnight.

\section{Antimicrobial activity of oil and liquid smoke assayed by disk diffusion method}

Disk diffusion method was performed as the preliminary assay for the determination of antibacterial activity of essential oil in combination with liquid smoke. The test was carried out in sterile Petri dishes (100 $\mathrm{mm}$ in diameter) containing $20 \mathrm{~mL}$ of Mueller-Hinton agar medium
(HiMedia, Mumbai, India). The combinations of different volumes of each, essential oil and liquid smoke (5, 10, 15 and $20 \mu \mathrm{L}$ ) were applied separately to sterile filter paper discs (6 $\mathrm{mm}$ in diameter; HiMedia). The essential oil and liquid smoke fixed on sterile paper discs were placed on the surface of the medium on which $100 \mu \mathrm{L}$ of microbial suspension $\left(10^{6} \mathrm{CFU} / \mathrm{mL}\right)$ incubated overnight were distributed uniformly in TSB. A single filter paper disc was placed over the agar in a Petri dish to avoid any possible additional bacterial activity. All samples were incubated aerobically for $18 \mathrm{~h}$ at $37^{\circ} \mathrm{C}$, as this is the optimum growth temperature for Staphylococcus aureus. The antimicrobial activity was evaluated by measuring the diameter of inhibition zones against $S$. aureus formed around the disc expressed in mm. Antibiotic discs of vancomycin $(30 \mathrm{mg} /$ disc) were used as positive control, whereas distilled water was used as a negative control. All the tests were performed in duplicates (36 plates), and values were expressed as mean with standard deviation.

\section{Determination of antimicrobial activity of oil and liquid smoke by checkerboard assay}

To investigate the combined effect of essential oil and liquid smoke against $S$. aureus, initial inocula mentioned in the previous section were used, and the method described by White et al. (17) was applied using checkerboard microtiter plates in triplicate. The MIC value of each antimicrobial agent in combination varied from $1 / 32$ to 4 times. A volume of $300 \mu \mathrm{L}$ of each dilution was added to the wells of two honeycomb microplates. Afterwards, each well was inoculated with $50 \mu \mathrm{L}$ of Staphylococcus aureus bacterial suspension $\left(10^{5} \mathrm{CFU} /\right.$ well $)$ and cultivated at $37^{\circ} \mathrm{C}$ for $24 \mathrm{~h}$. Fractional inhibitory concentration (FIC) of each antimicrobial agent was calculated as the MIC of the combination of E. platyloba essential oil (EO) with liquid smoke (LS), divided by the MIC of essential oil and liquid smoke alone. The used formulae to calculate the FIC values were as follows:

$$
\begin{gathered}
\mathrm{FIC}(\mathrm{EO})=\mathrm{MIC}(\mathrm{EO}+\mathrm{LS}) / \mathrm{MIC}(\mathrm{EO}) \\
\mathrm{FIC}(\mathrm{LS})=\mathrm{MIC}(\mathrm{EO}+\mathrm{LS}) / \mathrm{MIC}(\mathrm{LS}) \\
\mathrm{FIC}_{\text {index }}=\mathrm{FIC}(\mathrm{EO})+\mathrm{FIC}(\mathrm{LS})
\end{gathered}
$$

The $\mathrm{FIC}_{\text {index, }}$ which represents a combined effect of both antimicrobial agents, was interpreted as follows: if the $\mathrm{FIC}_{\text {index }}$ was $<1.0$ (on average $\leq 0.5$ ) the effect of essential oil and liquid smoke was synergistic; when $\mathrm{FIC}_{\text {index }}=1$ (on average $\geq 0.5$ ) the effect was additive; when $\mathrm{FIC}_{\text {index }}=2.0$ the effect was indifferent and at $\mathrm{FIC}_{\text {index }} \geq 2.0$ (on average $\geq 2.0$ or $\leq 4.0$ ) it was antagonistic. The generation (doubling) time $\left(t_{\mathrm{g}}\right)$ of $S$. aureus in meat samples treated with the combination of essential oil and liquid smoke was assessed using growth curves. Doubling of turbidity was detected as an increase of the absorbance from 0.4 to 0.8 . Each of the selected absorbances (18) was plotted against time. The doubling time in the exponential growth phase was calculated as follows:

$$
t_{\mathrm{g}}=t_{1}\left(A_{1}\right)-t_{2}\left(A_{2}\right)
$$

where $t_{1}$ is time at $A_{1}=0.8$ and $t_{2}$ is time at $A_{2}=0.4$. 


\section{Cytoplasmic material release}

The method proposed by Rhayour et al. (19) was followed to measure the absorbance of the released Staphylococcus aureus cell constituents into the supernatant at 260 $\mathrm{nm}$. Viable cells from $100 \mathrm{~mL}$ of $S$. aureus culture in the exponential growth phase were obtained by centrifugation (model Symphony 4417R; VWR International, Radnor, PA, USA) for $15 \mathrm{~min}$ at $8000 \times g$, then washed two to three times, and resuspended in $0.1 \mathrm{M}$ phosphate buffer saline solution ( $\mathrm{pH}=7.0)$ (Merck Millipore). A volume of $25 \mathrm{~mL}$ of cell suspension with $5 \%$ Tween 80 was incubated under agitation for $1 \mathrm{~h}$ at $37^{\circ} \mathrm{C}$ with the addition of essential oil and liquid smoke at 16 different volume ratios, ranging from $1 / 2 \mathrm{MIC}$ to $2 \mathrm{MIC}$. After incubation, 10 $\mathrm{mL}$ of samples were collected and centrifuged at $11000 \times \mathrm{g}$ for $15 \mathrm{~min}$. The absorbance of the supernatant was determined using UV-Vis spectrophotometer (Cecil Instruments Ltd, Cambridge, UK).

\section{Sensory analysis}

The organoleptic evaluation of the treated meat samples was done by nine trained persons who were selected among the students and staff of Shahid Beheshti University of Tehran, Iran. Four training sessions were designed to improve the ability of the panellists to recognise and quantify the sensory perception. All meat samples treated with different mass fractions of essential oil and liquid smoke were labelled with three digits, placed in aluminium foil, steamed in a simulated steam cooker at $100^{\circ} \mathrm{C}$ for $15 \mathrm{~min}$ and served on white plates. The panellists evaluated the overall acceptance of warm samples and were asked to cleanse their palate with low-salt crackers and water prior to the testing and between the samples. A hedonic scale from 1 to 5 , where $1=$ dislike extremely, $2=$ dislike moderately, $3=$ neither like nor dislike, $4=$ like moderately, and $5=$ like extremely, was used.

\section{Statistical analysis}

All of the assays were performed in triplicate. All growth curves were recorded and plotted in Microsoft Office Excel 2010 v. 14 (Microsoft Corporation, Redmond, WA, USA). The obtained results are expressed as the mean value \pm standard deviation. The results of sensory and disk diffusions assays were subjected to statistical analysis of variance using the general one-way ANOVA followed by Tukey's test. With the help of the SPSS software v. 17 (SPSS Inc, Chicago, IL, USA), significant differences between the control and the samples with added essential oil and liquid smoke were evaluated $(p<0.05)$.

\section{Results}

\section{Echinophora platyloba oil yield and chemical composition}

The obtained oil yield was $(0.80 \pm 0.05) \%$. The highest yield was obtained immediately after grinding the dried plant material, but the pulverised plant samples used for oil extraction did not have any significant effect on oil yield.

The main components of E. platyloba oil are listed in Table 1, which shows that 25 compounds were identified,
Table 1. Results of GC-MS analysis of the essential oil extracted from Echinophora platyloba aerial parts

\begin{tabular}{|c|c|c|c|}
\hline No. & Compound & RI & Peak area/\% \\
\hline 1 & $n$-Nonane & 900 & 0.21 \\
\hline 2 & $\alpha$-Tujene & 930 & 0.08 \\
\hline 3 & $\alpha$-Pinene & 939 & 3.33 \\
\hline 4 & Camphene & 953 & 0.25 \\
\hline 5 & Sabinene & 975 & 0.37 \\
\hline 6 & $\beta$-Pinene & 979 & 0.21 \\
\hline 7 & Myrcene & 991 & 1.18 \\
\hline 8 & $\alpha$-Phellandrene & 1003 & 2.57 \\
\hline 9 & p-Cymene & 1025 & 3.79 \\
\hline 10 & $\beta$-Phellandrene & 1030 & 0.46 \\
\hline 11 & (Z)- $\beta$-Ocimene & 1037 & 73.26 \\
\hline 12 & $\gamma$-Terpinene & 1060 & 1.13 \\
\hline 13 & Linalool & 1097 & 0.55 \\
\hline 14 & Alloocimene & 1132 & 0.60 \\
\hline 15 & $p$-Menth-2-en-1-ol & 1139 & 1.48 \\
\hline 16 & $p$-Mentha-1,5-dien-8-ol & 1143 & 0.17 \\
\hline 17 & $\alpha$-Terpineol & 1176 & 0.13 \\
\hline 18 & cis-3-Hexenyl-2-methyl butanoate & 1214 & 0.71 \\
\hline 19 & cis-3-Hexenyl isovalerate & 1216 & 1.18 \\
\hline 20 & $\alpha$-Terpinenyl acetate & 1335 & 0.21 \\
\hline 21 & Methyleugenol & 1369 & 0.50 \\
\hline 22 & 4-Decanolide & 1429 & 0.25 \\
\hline 23 & 2-Furanone & 1466 & 2.57 \\
\hline 24 & cis-3-Hexenyl benzoate & 1568 & 0.67 \\
\hline 25 & Spathunenol & 1577 & 1.40 \\
\hline
\end{tabular}

RI=retention index

representing $97.26 \%$ of the oil. $\beta$-Ocimene $(73.26 \%)$ was found as the major constituent, besides other constituents with relatively low fractions including $p$-cymene $(3.79 \%)$, $\alpha$-pinene (3.33\%) and $\alpha$-phellandrene (2.57\%). These results suggest that the extracted essential oil has a high level of antimicrobial activity.

\section{Content of polycyclic aromatic hydrocarbons in liquid smoke}

The content of polycyclic aromatic hydrocarbons (PAH) in liquid smoke is shown in Table 2. Liquid smoke used for sensory evaluation contained less than $2 \mu \mathrm{g} / \mathrm{kg}$ of benzo[a]pyrene as an indicator (highly carcinogenic).

\section{Antistaphylococcal activity of essential oil and liquid smoke alone}

MIC values of E. platyloba essential oil and liquid smoke against Staphylococcus aureus are 7200 and $5500 \mathrm{mg} / \mathrm{L}$, and MBC values are 8500 and $8000 \mathrm{mg} / \mathrm{L}$, respectively. MBC values of E. platyloba essential oil and liquid smoke were almost similar, and they were 1.5 times higher than MIC values. Liquid smoke MIC value is lower than of E. platyloba, which can be interpreted as a higher antimicrobial activity of the former against Staphylococcus aureus. 
Table 2. Mass concentrations of 12 polycyclic aromatic hydrocarbons (PAH) in liquid smoke

\begin{tabular}{rlrc}
\hline No. & PAH & $t_{\mathrm{R}} / \mathrm{min}$ & $\gamma /(\mathrm{g} / \mathrm{L})$ \\
\hline 1 & Naphthalene & 8.063 & 0.216 \\
2 & Acenaphthylene & 12.362 & 1.320 \\
3 & Acenaphthene & 12.825 & 0.678 \\
4 & Fluorene & 14.554 & 0.106 \\
5 & Phenanthrene & 18.761 & 0.178 \\
6 & Anthracene & 19.026 & 0.346 \\
7 & Fluoranthene & 25.427 & 0.548 \\
8 & Pyrene & 26.467 & 0.684 \\
9 & Benz[a]anthracene & 31.760 & 1.284 \\
10 & Benzo[b]fluoranthene & 31.955 & 1.482 \\
11 & Benzo[a]pyrene & 38.222 & 1.908 \\
12 & Dibenz[a,h]anthracene & 40.852 & 2.400 \\
\hline
\end{tabular}

\section{Antistaphylococcal activity of essential oil and liquid smoke in combination}

In Table 3 the antimicrobial activity (inhibition zone diameter) of different combinations of the essential oil and liquid smoke against Staphylococcus aureus is demonstrated. The values given in the table are classified into two groups: one in which the value of liquid smoke is constant and of the essential oil is varied, and the other in which

Table 3. Inhibition of Staphylococcus aureus growth by Echinophora platyloba essential oil (EO) and liquid smoke (LS) in combination

\begin{tabular}{|c|c|c|c|}
\hline$V(\mathrm{LS}+\mathrm{EO})$ & $d$ (inhibition) & $V(\mathrm{EO}+\mathrm{LS})$ & $d$ (inhibition) \\
\hline$\mu \mathrm{L}$ & $\mathrm{mm}$ & $\mu \mathrm{L}$ & $\mathrm{mm}$ \\
\hline $5+5$ & $(21.0 \pm 0.0)^{\mathrm{a}}$ & $5+5$ & $(21.0 \pm 0.0)^{\mathrm{a}}$ \\
\hline $5+10$ & $(20.5 \pm 0.7)^{\mathrm{a}}$ & $5+10$ & $(25.0 \pm 0.0)^{\mathrm{b}}$ \\
\hline $5+15$ & $(20.0 \pm 0.0)^{\mathrm{a}}$ & $5+15$ & $(28.5 \pm 0.7)^{c}$ \\
\hline $5+20$ & $(21.5 \pm 0.7)^{\mathrm{a}}$ & $5+20$ & $(32.5 \pm 0.7)^{\mathrm{d}}$ \\
\hline $10+5$ & $(25.0 \pm 0.0)^{\mathrm{a}}$ & $10+5$ & $(20.5 \pm 0.7)^{a}$ \\
\hline $10+10$ & $(25.0 \pm 0.0)^{\mathrm{a}}$ & $10+10$ & $(25.0 \pm 0.0)^{\mathrm{b}}$ \\
\hline $10+15$ & $(26.0 \pm 1.4)^{\mathrm{a}}$ & $10+15$ & $(27.0 \pm 0.0)^{c}$ \\
\hline $10+20$ & $(25.5 \pm 0.7)^{\mathrm{a}}$ & $10+20$ & $(30.0 \pm 0.0)^{\mathrm{d}}$ \\
\hline $15+5$ & $(28.5 \pm 0.7)^{\mathrm{ab}}$ & $15+5$ & $(20.0 \pm 0.0)^{\mathrm{a}}$ \\
\hline $15+10$ & $(27.0 \pm 0.0)^{\mathrm{a}}$ & $15+10$ & $(26.0 \pm 1.4)^{\mathrm{b}}$ \\
\hline $15+15$ & $(29.5 \pm 0.7)^{\mathrm{b}}$ & $15+15$ & $(29.5 \pm 0.7)^{c}$ \\
\hline $15+20$ & $(29.5 \pm 0.7)^{\mathrm{b}}$ & $15+20$ & $(31.5 \pm 0.7)^{\mathrm{d}}$ \\
\hline $20+5$ & $(32.5 \pm 0.7)^{\mathrm{a}}$ & $20+5$ & $(21.5 \pm 0.7)^{\mathrm{a}}$ \\
\hline $20+10$ & $(30.0 \pm 0.0)^{\mathrm{a}}$ & $20+10$ & $(25.5 \pm 0.7)^{\mathrm{b}}$ \\
\hline $20+15$ & $(31.5 \pm 0.7)^{\mathrm{a}}$ & $20+15$ & $(29.5 \pm 0.7)^{\mathrm{bc}}$ \\
\hline $20+20$ & $(29.0 \pm 1.4)^{\mathrm{a}}$ & $20+20$ & $(29.0 \pm 1.4)^{c}$ \\
\hline
\end{tabular}

Inhibition zone represents the mean value \pm standard deviation of the antimicrobial activity of liquid smoke and essential oil in combination.

Mean values with different letters within the same group are significantly different at $p<0.05$.

Control values are $23.5 \pm 0.5$ for positive control (vancomycin) and $0.0 \pm 0.0$ for negative control (distilled water) the volume of essential oil is constant and that of liquid smoke is varied. Results are reported as mean values \pm standard deviation of triplicate experiments $(p<0.05)$.

As the volume of the essential oil and liquid smoke was increased, the inhibition zone increased in all of the samples $(p<0.05)$. The discs containing $20 \mu \mathrm{L}$ of liquid smoke and $5 \mu \mathrm{L}$ of essential oil, and $15 \mu \mathrm{L}$ of essential oil and $5 \mu \mathrm{L}$ of liquid smoke had the highest and lowest zone of inhibition, respectively $(\mathrm{p}<0.05)$.

The $\mathrm{FIC}_{\text {index }}$ of the essential oil combined with the liquid smoke was measured to be 2.031 (data not shown), which indicates that the mixture constituents had an antagonistic effect. The results of $S$. aureus generation time measurement during its exponential growth phase are shown in Table 4 . The generation time of $S$. aureus treated with essential oil and liquid smoke at different MIC values was significantly increased $(p<0.05)$. Double MIC of the mixture did not inhibit the $S$. aureus growth but had a positive effect on generation time $(\mathrm{p}<0.05)$. The generation time was significantly increased when higher volumes of antimicrobial agents were used, except at the MIC value.

Table 4. Staphylococcus aureus generation time after the treatment with essential oil (EO) and liquid smoke (LS) mixture

\begin{tabular}{crrrrrr}
\hline & \multicolumn{6}{c}{ MIC(LS) } \\
\cline { 2 - 7 } MIC(EO) & 1 & $1 / 2$ & $1 / 4$ & $1 / 8$ & $1 / 16$ & $1 / 32$ \\
\cline { 2 - 7 } & $195^{*}$ & $165^{*}$ & $135^{*}$ & $150^{*}$ & $135^{*}$ & $165^{*}$ \\
\hline 2 & $165^{*}$ & $120^{*}$ & $105^{*}$ & $105^{*}$ & $105^{*}$ & $120^{*}$ \\
1 & $120^{*}$ & $105^{*}$ & 90 & 90 & 90 & 90 \\
$1 / 2$ & $120^{*}$ & 90 & 75 & 75 & 75 & 75 \\
$1 / 4$ & $120^{*}$ & 90 & 75 & 75 & 75 & 90 \\
$1 / 8$ & $165^{*}$ & 90 & 90 & 75 & 75 & 75 \\
$1 / 16$ & $135^{*}$ & $105^{*}$ & 90 & 75 & 75 & 75 \\
\hline
\end{tabular}

$\mathrm{MIC}=$ minimum inhibitory concentration ${ }^{*} p<0.05$ as compared to the control

\section{Results of sensory analysis}

The sensory properties of minced beef treated with essential oil and liquid smoke are given in Table 5. The sensory attribute was acceptable by the panellists when $0.05 \mathrm{~g}$ of essential oil and $0.6 \mathrm{~g}$ of liquid smoke were added to $100 \mathrm{~g}$ of meat. However, unacceptable odour related to the presence of essential oil in minced meat was reported when $0.06 \mathrm{~g}$ or more were added.

\section{Cell constituent release}

The results of $A_{260 \mathrm{~nm}}$ values of $S$. aureus cells (amino acids, nucleotides and ions) when treated with E. platyloba essential oil and liquid smoke at four concentrations (i.e. 0 MIC, 1/2 MIC, MIC, and 2 MIC value) are 0.0, 0.36, 0.72 and 1.44 , and $0.0,0.275,0.55$ and 1.1 , respectively (Fig. 1). In total, there are 16 combinations of essential oil and liquid smoke values.

It can be concluded that with increasing the volume of essential oil and liquid smoke (Fig. 1), alone and in combination, absorbance was increased. Higher antimi- 
Table 5. Overall acceptance evaluation of minced beef treated with essential oil (EO) and liquid smoke (LS)

\begin{tabular}{cccc}
\hline$w(\mathrm{EO}) / \%$ & Score & $w(\mathrm{LS}) / \%$ & Score \\
\hline 0.03 & $(1.9 \pm 1.0)^{\mathrm{ab}}$ & 0.5 & $(3.2 \pm 1.4)^{\mathrm{a}}$ \\
0.04 & $(2.4 \pm 1.3)^{\mathrm{ab}}$ & 0.6 & $(3.8 \pm 0.9)^{\mathrm{a}}$ \\
0.05 & $(2.4 \pm 1.3)^{\mathrm{a}}$ & 0.7 & $(3.3 \pm 1.0)^{\mathrm{a}}$ \\
0.06 & $(2.1 \pm 0.8)^{\mathrm{b}}$ & 0.8 & $(3.2 \pm 1.0)^{\mathrm{a}}$ \\
\hline
\end{tabular}

Scores represent the mean value \pm standard deviation, $N=9$. Mean values with different letters within the same column are significantly different compared to controls $(\mathrm{p}<0.05)$.

Control values are $3.8 \pm 1.0$ for essential oil and $3.7 \pm 1.1$ for liquid smoke

crobial activity was found in the samples treated with higher volumes of essential oil or liquid smoke (e.g. 0:1.1 and 1.44:0) than with lower volumes of both essential oil and liquid smoke when they are combined (e.g. 0.36:0.275 or $0.36: 0.55)$.

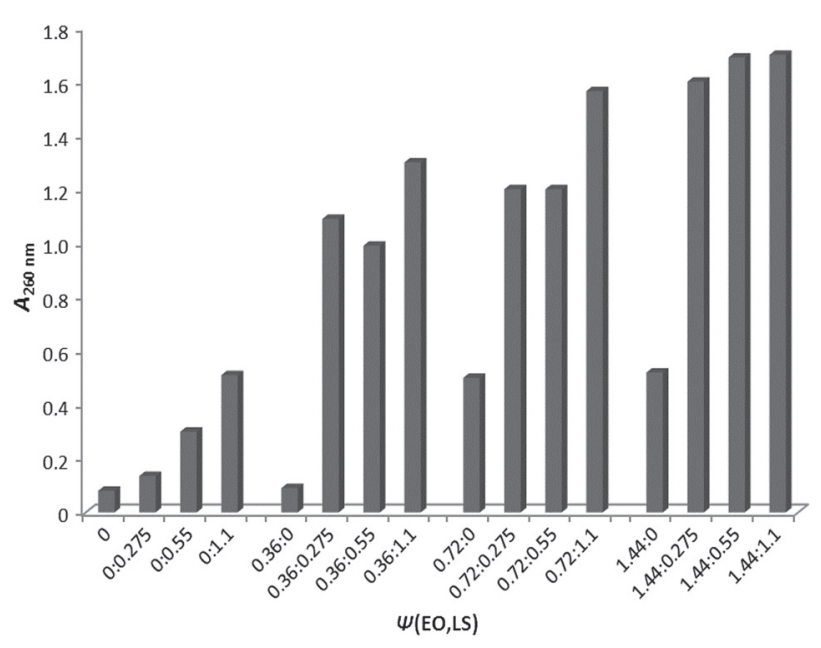

Fig. 1. Comparison of the release of absorbing material from $S$. aureus cells treated with Echinophora platyloba essential oil (EO) and liquid smoke (LS) at different volume ratios

\section{Discussion}

The yield of Echinophora platyloba oil obtained after hydrodistillation was $0.8 \%$, which is higher than previously reported values of 0.55 (6), 0.67 (14) and $0.7 \%$ (20), perhaps due to the variation of sowing date and water stress (21), sampling time, geographical origin or genetic differences (22).

Essential oils are natural products. Despite the genetic factors, all environmental conditions and geographical origin have an influence on their chemical constituents (23). Results showed that essential oil mainly consists of hydrocarbon monoterpenes which, unlike phenolic compounds, generally accumulate in higher amounts in cooler and damper areas (24). The concentrations of hydrocarbon monoterpenes in the current study are comparable to the results reported by Hassanpouraghdam et al. (15), as in both cases similar damp and cool geographical origin of E. platyloba plant can be a possible reason for their higher concentrations than in other studies. Based on the experiments of Ghani et al. (25), the high monoterpene ratio is constant during three different growth and developmental stages.

It is interesting to note that the same E. platyloba species harvested in Kermanshah (200 km west of Hamadan, Iran) but treated with a different extraction method (microwave distillation) had a slightly different composition (26).

However, more than one compound of essential oils possesses the overall antibacterial activity (27). The extracted essential oil from E. platyloba has a high concentration of $\beta$-ocimene, which is responsible for its antimicrobial activity. Also, $\alpha$-pinene can be considered as an active antibacterial agent against Staphylococcus aureus (28).

Benzo[a]-pyrene, a marker of the carcinogenic PAHs in food, was found in the analysed liquid smoke below the maximum recommended level by European Scientific Committee on Food ( $2 \mu \mathrm{g} / \mathrm{kg}$ ) (29). Therefore, the acceptable concentration of liquid smoke (according to sensory evaluation) is considered to be safe.

Both E. platyloba essential oil and liquid smoke exhibited a significant antibacterial activity against Staphylococcus aureus. The liquid smoke tested in this study was found to be more effective than the essential oil.

Antagonistic effect between constant volumes of liquid smoke $(5,10$ and $20 \mu \mathrm{L})$ and different volumes of essential oil was determined by disk diffusion method, whereas there was a significant increase of antibacterial activity when constant volume of liquid smoke was added to 5,10 or $15 \mu \mathrm{L}$ of essential oil. As shown in Table 3, the lowest volumes of essential oil and liquid smoke did not show the minimum antimicrobial effect, while higher volumes resulted in a decrease of antimicrobial activity. Previously, the synergic effect of the mixture of the essential oil and acetic acid was demonstrated. The acid dissociation results in the release of $\mathrm{H}^{+}$ions, which lower the $\mathrm{pH}$ and damage cell membranes of bacteria, thus increasing the effectiveness of essential oil components such as phenols (30).

Antagonistic interactions between the oil and the liquid smoke flavour were explored by checkerboard method. The possible explanations of antagonistic interactions were not well demonstrated $(31,32)$. The antagonistic effect has been attributed to the interaction between non-oxygenated and oxygenated monoterpene hydrocarbons (13).

The result of generation time assays of Staphylococcus aureus treated with essential oil and liquid smoke mixture showed that the growth was inhibited by liquid smoke at 2 MIC, whereas essential oil did not show the same effect. Therefore, liquid smoke in the presence of the essential oil was expected to prolong doubling time but not to inhibit the growth completely.

The increase in $A_{260 \mathrm{~nm}}$ is consistent with the release of amino acids, nucleotides, and ions from $S$. aureus cells due to cell membrane damage when treated with E. platyloba and liquid smoke at four different concentrations. The release of cellular content of the treated bacteria led to the hypothesis that the primary effect of an essential oil is membrane disruption. E. platyloba contains terpenes which can penetrate or disrupt lipid structures. The hy- 
drophobicity of essential oil enables it to divide the bacterial cell membrane and mitochondria which are composed of the phospholipid bilayer. This resulted in the damage of the structure of bacteria and rendering of the cells more permeable, leading to an increase of ion permeability or leakage of cell content and impairment of bacterial enzyme systems (33). Rhayour et al. (19) claimed that the observed damage in Gram-positive bacteria could be related to cell deformation. Extensive loss of vital intracellular constituents in bacteria would eventually lead to cell death (34).

The sensory properties of minced beef treated with essential oil showed that the addition of $0.05 \mathrm{~g}$ of E. platyloba essential oil to $100 \mathrm{~g}$ of meat has a positive effect on the acceptance of the product. Also, the liquid smoke at higher mass fraction of $0.6 \mathrm{~g}$ per $100 \mathrm{~g}$ of meat (more than ten times of that of the essential oil) did not affect organoleptic properties of minced meat.

\section{Conclusions}

The combination of Echinophora platyloba essential oil and liquid smoke could be applied to minced meat products without any off-taste. According to the results of sensory evaluation, the added mass fractions of essential oil and liquid smoke $(0.05$ and $0.6 \mathrm{~g}$ per $100 \mathrm{~g}$ of meat, respectively) to minced beef had no adverse effect on the overall acceptance. The conducted experiments showed that liquid smoke had a better antimicrobial activity against Staphylococcus aureus than E. platyloba essential oil. Moreover, we observed that both antimicrobial agents showed a weak antimicrobial effect against $S$. aureus when used alone, and that the combination of essential oil with liquid smoke did not improve its antibacterial effect, although it may increase the minimum effective dose of these compounds. Therefore, further investigations are recommended to find ways for improving the antimicrobial effect of this essential oil in combination with other antimicrobial agents.

\section{Acknowledgements}

This work was supported financially by the Student Research Committee, Shahid Beheshti University of Medical Sciences, project no. 1395-77359. We are grateful to Dr. Chris Michiels of the Centre for Food and Microbial Technology, Leuven, Belgium, for his valuable consultancy during this research. A. Mousavi Khaneghah likes to thank for the support of CNPq-TWAS Postgraduate Fellowship (grant no. 324027 4290).

\section{References}

1. Acco M, Ferreira FS, Henriques JAP, Tondo EC. Identification of multiple strains of Staphylococcus aureus colonizing nasal mucosa of food handlers. Food Microbiol. 2003;20: 489-93.

http://dx.doi.org/10.1016/S0740-0020(03)00049-2

2. Behling RG, Eifert J, Erickson MC, Gurtler JB, Kornacki JL, Line E, et al. Selected pathogens of concern to industrial food processors: infectious, toxigenic, toxico-infectious, selected emerging pathogenic bacteria In: Kornacki LJ, editor. Principles of microbiological troubleshooting in the industrial food processing environment, food microbiology and food safety. New York, NY, USA: Springer; 2010. pp. 5-61. http://dx.doi.org/10.1007/978-1-4419-5518-0_2

3. Doyle MP, Buchanan RL. Food microbiology: fundamentals and frontiers. Washington, DC, USA: ASM Press; 2013.

4. Djenane D, Aïder M, Yangüela J, Idir L, Gómez D, Roncalés P. Antioxidant and antibacterial effects of Lavandula and Mentha essential oils in minced beef inoculated with E. coli O157:H7 and S. aureus during storage at abuse refrigeration temperature. Meat Sci. 2012;92:667-74. http://dx.doi.org/10.1016/j.meatsci.2012.06.019

5. de Barros JC, da Conceição ML, Gomes Neto NJ, da Costa ACV, de Souza EL. Combination of Origanum vulgare L. essential oil and lactic acid to inhibit Staphylococcus aureus in meat broth and meat model. Braz J Microbiol. 2012;43:1120-7. http://dx.doi.org/10.1590/S1517-838220120003000039

6. Asghari J, Touli CK, Mazaheritehrani M. Microwave-assisted hydrodistillation of essential oils from Echinophora platyloba DC. J Med Plants Res. 2012;6:4475-80. http://dx.doi.org/10.5897/jmpr011.982

7. Avijgan M, Hafizi M, Saadat M, Nilforoushzadeh MA. Antifungal effect of Echinophora Platyloba's extract against Candida albicans. Iran J Pharm Res. 2010;5:285-9.

8. Pilevar Z, Hosseini H. Chemical composition, antimicrobial and antioxidant activity of Echinophora platyloba DC. J Pharm Nutr Sci. 2013;3:270-83. http://dx.doi.org/10.6000/1927-5951.2013.03.04.10

9. Lingbeck JM, Cordero P, O’Bryan CA, Johnson MG, Ricke SC, Crandall PG. Functionality of liquid smoke as an all-natural antimicrobial in food preservation. Meat Sci. 2014;97: 197-206. http://dx.doi.org/10.1016/j.meatsci.2014.02.003

10. Kamankesh M, Mohammadi A, Hosseini H, Tehrani ZM. Rapid determination of polycyclic aromatic hydrocarbons in grilled meat using microwave-assisted extraction and dispersive liquid-liquid microextraction coupled to gas chromatography-mass spectrometry. Meat Sci. 2015;103:61-7. http://dx.doi.org/10.1016/j.meatsci.2015.01.001

11. Varlet V, Serot T, Prost C. Smoke flavoring technology in seafood. In: Nollet LML, Toldra F, editors. Handbook of seafood and seafood products analysis. Boca Raton, FL, USA: CRC Press; 2009. pp. 233-54. http://dx.doi.org/10.1201/9781420046359-c15

12. Holley RA, Patel D. Improvement in shelf-life and safety of perishable foods by plant essential oils and smoke antimicrobials. Food Microbiol. 2005;22:273-92. http://dx.doi.org/10.1016/j.fm.2004.08.006

13. Bassole IHN, Lamien-Meda A, Bayala B, Obame LC, Ilboudo AJ, Franz C, et al. Chemical composition and antimicrobial activity of Cymbopogon citratus and Cymbopogon giganteus essential oils alone and in combination. Phytomedicine. 2011;18:1070-4.

http://dx.doi.org/10.1016/j.phymed.2011.05.009

14. Gholivand MB, Rahimi-Nasrabadi M, Mehraban E, Niasari M, Batooli H. Determination of the chemical composition and in vitro antioxidant activities of essential oil and methanol extracts of Echinophora platyloba DC. Nat Prod Res. 2011;25:1585-95. http://dx.doi.org/10.1080/14786419.2010.490915

15. Hassanpouraghdam MB, Shalamzari MS, Sepehri N. GC/MS analysis of Echinophora platyloba DC. essential oil from Northwest Iran: a potential source of (Z)- $\beta$-ocimene and $\alpha$-phellandrene. Chemija. 2009;20:120-3.

16. Wiegand I, Hilpert K, Hancock RE. Agar and broth dilution methods to determine the minimal inhibitory concentration (MIC) of antimicrobial substances. Nat Protocols. 2008;3:16375 . http://dx.doi.org/10.1038/nprot.2007.521 
17. White RL, Burgess DS, Manduru M, Bosso JA. Comparison of three different in vitro methods of detecting synergy: time-kill, checkerboard, and E test. Antimicrob Agents Chemother. 1996;40:1914-8.

18. Harley JP. Laboratory exercises in microbiology. New York, NY, USA: The McGraw-Hill Companies; 2004.

19. Rhayour K, Bouchikhi T, Tantaoui-Elaraki A, Sendide K, Remmal A. The mechanism of bactericidal action of oregano and clove essential oils and of their phenolic major components on Escherichia coli and Bacillus subtilis. J Essent Oil Res. 2003;15:286-92.

http://dx.doi.org/10.1080/10412905.2003.9712144

20. Saei-Dehkordi SS, Fallah AA, Saei-Dehkordi SS, Kousha S. Chemical composition and antioxidative activity of Echinophora platyloba DC. Essential oil, and its interaction with natural antimicrobials against food-borne pathogens and spoilage organisms. J Food Sci. 2012;77:M631-7. http://dx.doi.org/10.1111/j.1750-3841.2012.02956.x

21. Flagella Z, Rotunno T, Tarantino E, Di Caterina R, De Caro A. Changes in seed yield and oil fatty acid composition of high oleic sunflower (Helianthus annuus L.) hybrids in relation to the sowing date and the water regime. Eur J Agron. 2002;17:221-30. http://dx.doi.org/10.1016/S1161-0301(02)00012-6

22. Saei-Dehkordi SS, Tajik H, Moradi M, Khalighi-Sigaroodi F. Chemical composition of essential oils in Zataria multiflora Boiss. from different parts of Iran and their radical scavenging and antimicrobial activity. Food Chem Toxicol. 2010;48: 1562-7.

23. Bakkali F, Averbeck S, Averbeck D, Idaomar M. Biological effects of essential oils-a review. Food Chem Toxicol. 2008;46: $446-75$.

http://dx.doi.org/10.1016/j.fct.2007.09.106

24. Ložienė K, Šakalytė J, Paškevičius A, Venskutonis PR. AntiCandida activity of Thymus pulegioides (Lamiaceae) essential oils depends on the plant chemotype. Herba Pol. 2008;54: 79-92.

25. Ghani A, Saharkhiz M, Hassanzadeh M, Msaada K. Changes in the essential oil content and chemical compositions of Echinophora platyloba DC. during three different growth and developmental stages. J Essent Oil Bear Pl. 2009;12:16271

http://dx.doi.org/10.1080/0972060X.2009.10643706
26. Gholivand MB, Abolghasemi MM, Piryaei M, Maassoumi SM, Papzan A. Microwave distillation followed by headspace single drop microextraction coupled to gas chromatography-mass spectrometry (GC-MS) for fast analysis of volatile components of Echinophora platyloba DC. Food Chem. 2013;138:251-5. http://dx.doi.org/10.1016/j.foodchem.2012.09.112

27. Koutsoudaki C, Krsek M, Rodger A. Chemical composition and antibacterial activity of the essential oil and the gum of Pistacia lentiscus var. chia. J Agric Food Chem. 2005;53: 7681-5. http://dx.doi.org/10.1021/jf050639s

28. Raman A, Weir U, Bloomfield S. Antimicrobial effects of teatree oil and its major components on Staphylococcus aureus, Staph. epidermidis and Propionibacterium acnes. Lett Appl Microbiol. 1995;21:242-5.

http://dx.doi.org/10.1111/j.1472-765X.1995.tb01051.x

29. Commission Regulation (EU) No 835/2011 of 19 August 2011 amending Regulation (EC) No 1881/2006 as regards maximum levels for polycyclic aromatic hydrocarbons in foodstuffs. Off J EU. 2011;L215:4-8.

30. Juven BJ, Kanner J, Schved F, Weisslowicz H. Factors that interact with the antibacterial action of thyme essential oil and its active constituents. J Appl Bacteriol. 1994;76:626-31. http://dx.doi.org/10.1111/j.1365-2672.1994.tb01661.x

31. Miladinović DL, Ilić BS, Kocić BD, Miladinović LC, Marković MS. In vitro interactions of Peucedanum officinale essential oil with antibiotics. Nat Prod Res. 2015;29:972-5. http://dx.doi.org/10.1080/14786419.2014.958740

32. Goñi P, López P, Sánchez C, Gómez-Lus R, Becerril R, Nerin C. Antimicrobial activity in the vapour phase of a combination of cinnamon and clove essential oils. Food Chem. 2009; 116:982-9. http://dx.doi.org/10.1016/j.foodchem.2009.03.058

33. Cristani M, D'Arrigo M, Mandalari G, Castelli F, Sarpietro MG, Micieli D, et al. Interaction of four monoterpenes contained in essential oils with model membranes: implications for their antibacterial activity. J Agric Food Chem. 2007;55: $6300-8$. http://dx.doi.org/10.1021/jf070094x

34. Sikkema J, de Bont J, Poolman B. Interactions of cyclic hydrocarbons with biological membranes. J Biol Chem. 1994; 269:8022-8. 